\title{
A Feasibility Study of Wood-plastic Composite Paver Block for Basic Rest Areas ${ }^{1}$
}

\author{
Sungchul Yang (D) ${ }^{2, \dagger}$
}

\begin{abstract}
A wood-plastic composite (WPC) paver block was manufactured using wood chips waste through an extrusion process, and it was intended to be used for paving in basic rest areas. The first stage in this study covered preliminary tests in terms of flexural strength and dimensional swelling to determine the optimal WPC compounding mix condition, by variation of the WPC ingredients. Next, three different paver blocks including the WPC block, a non-porous cement block, and a porous cement block were tested in terms of various material properties in the laboratory. Finally, two outdoor test sections of the proposed paver blocks were prepared to simulate a basic rest area. Test results indicated that the flexural strength of the WPC paver blocks was about 1.6 times greater than that of the tested cement paver blocks. The WPC block pavement was unaffected by water buoyance as well as volume expansion due to swelling. Results from the impact absorbance test and light falling weight deflectometer (LFWD) test clearly showed that the WPC block paving system marginally satisfied the comfortable and safe hardness range from the pedestrians' perspective, while the results demonstrated that it is structurally sound for application as a road paving block.
\end{abstract}

Keywords: wood plastic composite, recycled resources, block paver, impact absorbance, hardness

\section{INTRODUCTION}

Recently, South Korea’s National Statistics Office reported that deaths in traffic accidents on the nation's highways are due to several factors: $27 \%$ by vehicle defects, $19 \%$ by excessive speed, $23 \%$ by observation negligence, and $31 \%$ by drowsy driving (Ministry of Land, Infrastructure and Transport, 2018). To reduce drowsy driving accidents, which is a big factor in traffic fatalities, the South Korean government has established almost 270 basic rest areas at 10 minute-interval distances along highways from 2010 to 2017. During this period, the number of deaths in traffic accidents dropped by $55 \%$ with the introduction of the basic rest areas (Ministry of Land, Infrastructure and Transport, 2018).

Facilities in many rest areas include a park-like area, public toilets, and food trucks or restaurants with free Wi-Fi. On the other hand, the most basic rest areas have no facilities. They consist solely of an exit from the highway that leads to a roadway with paved shoulders, where drivers can rest, take a nap, look at their maps, or use their cell phones (Wikipedia, 2018).

Asphalt and concrete are the most common paving

\footnotetext{
${ }^{1}$ Date Received October 18, 2018, Date Accepted December 27, 2018

2 School of Architectural Engineering, College of Science and Technology, Hongik University, Sejong 30016, Republic of Korea

† Corresponding author: Sungchul Yang(e-mail: scyang@hongik.ac.kr, ORCID: 0000-0002-7955-6735)
} 
materials found in the rest areas along highways. There are other strong and durable pavement materials that can add variety to the built landscape, such as cement, clay, and stone blocks. All these paving materials are known to be suitable for road block pavement (Gibbons, 1999). In Finland, wood stone paver blocks, in which up to $50 \%$ of the rock material of regular concrete is replaced with decommissioned and recycled clean wood chips, have been proposed and commercially used both for sidewalk paving blocks and road paving blocks (Destamatic Oy, 2016).

The first use of timber blocks is reported to have been in Russia as early as the fourteenth century (Weiss, 2011). Wood paving blocks were introduced in New York in 1835, in London in 1841, in Paris about 1892, and in Sydney about 1894 (Weiss, 2011; Whitten, 1995; Whitten, 1997; Smith, 1894; Wittenoom, 1900; Richards, 1897; Stirrat, 1898).

The best pavement for horses at that time was wooden blocks. Horses' feet needed a soft roadway to avoid injury, while wagon wheels needed a hard pavement to reduce friction and increase efficiency (Brown, 2016). It was noted at those times that any horse on a hard pavement other than a soft roadway is under a continual strain, for it is constantly afraid of falling due to the slipperiness of the hard pavement. This is similar to a person is when walking on smooth ice due to its slipperiness (Brown, 2016). Wood blocks were considered appealing for streets near hospitals, schools, churches, and public buildings such as courthouses where noise was especially bothersome, and in congested street with heavy traffic. It was reported that the noise was hugely generated by hundreds of steel-tired wagon wheels and horseshoes on bricks, steel iron, or granite block streets surrounded by multileveled buildings (Whitten, 1997). Besides, advantages of wood-block pavement are durability, ease of repair (Weiss, 2011). The durability of wood-block when properly laid is surprising. Data from a test pavement in Minneapolis, when accurate traffic records are kept over one of the busiest streets in the city, show a wear of about $0.8 \mathrm{~mm}$ per year. To repair some damaged wood-blocks, all that is necessary is to remove them, smooth the sand cushion, and add new ones.

However, wood blocks were rarely replaced because they wore out too quickly and absorbed horse urine, which made them smell bad (Kyriakodis, 2014). Thus, many paving wood blocks are impregnated with coal-tar creosote, either alone or in mixture with tar (Weiss, 2011). Further, the department of streets had problems finding wood that was sufficiently dense (Kyriakodis, 2014). When there was wet weather, the wooden blocks expanded more than anticipated, loosened and came out (Kyriakodis, 2014). It has been stated that wood block paving at times has serious disadvantages (Weiss, 2011). The chief objections are slipperiness, exudation of oil, and expansion of the blocks (Weiss, 2011). In general, the harder the blocks are, the smoother the pavement becomes slippery. Oil and tar on the surface of the pavement also increases slipperiness. If sand embed itself in the wood, the surface of the blocks would become roughened (Weiss, 2011). The excess oil and tar may at times exude to the surface and form a thick disagreeable mat, which sticks to the feet of pedestrians and is generally objectionable. If the blocks are laid very dry and close together, there will be little room for expansion and the pavement will be very liable to buckle.

Wood block pavement still exist in several places in USA: Roslyn Place in Pittsburgh, Camac Street in Philadelphia, and Hessler Court in Cleveland, among others (Wikipedia, 2016). A historic wood paver restoration work has been attempted in George Street in Sydney (Sydney Harbor Foreshore Authority, 2012). To increase the density of wood block, natural coal tar was impregnated into wood blocks, and reinforcing bars were installed at the bottom of the block hole perhaps to hold light wood blocks against the buoyance 
of water (Sydney Harbor Foreshore Authority, 2012). Regardless of the efforts to preserve historic landmarks in Chicago and Sydney, wood block restoration projects these days are not currently being pursued for practical use. Those are limited only to preserve historic works.

In basic rest areas, the hardness of the sidewalk pavement blocks should be determined with consideration of the safety and comfort of users, especially the elderly. It is commonly accepted that repulsive force is higher in concrete and asphalt pavement materials (Nabeshima and Yamada, 2005; Takeuchi et al., 2008; Takeuchi et al., 2011; Higuchi et al., 2011; Choi and Lee, 2004; Choi et al., 2017). Moreover, concrete and asphalt are cheaper paving materials than block pavement. Nevertheless, it takes longer for concrete to cure so that it becomes as hard as stone. The disadvantages of bituminous materials are their relatively high installation and maintenance costs. Meanwhile, paver blocks are popular paving materials because they are easy to produce, easy to use in small areas, and readily available in a variety of shapes and colors (Destamatic Oy, 2016). However, disadvantages of paver blocks include crack, corner breaks, joint filler damage, and patch deterioration; thus, they may require more maintenance work than other types of paving. Wood and wood products are eco-friendly and lighter than other paving materials; thus, they are easy to install, strong and durable for their weight, and comfortable for pedestrians. However, they are not cheap, and swelling may occur because wood is susceptible to moisture variation (Ko and Ko, 2015).

There have been few implementation studies on sidewalks, square plazas, trails, and playgrounds paved with wood or wood products, such as wood plastic composites in Japan and South Korea (Nabeshima and Yamada, 2005; Takeuchi et al., 2008; Takeuchi et al., 2011; Higuchi et al., 2011; Choi and Lee, 2004; Choi et al., 2017; Ko and Ko, 2015). It is, however, surprising that wood block pavers were the main paving materials for the horse-powered carriages before the $20^{\text {th }}$ century and this relevant history is presented in Section 2.

Combining wood chips with plastics can overcome the disadvantage of brittleness, which is an inherent characteristic of cement blocks or brick block pavers, and they may have diverse interlocking patterns. In terms of appearance, wood blocks yield an elegant range of colors and living or natural textures (Destamatic Oy, 2016). Numerous pores distributed inside wood make it easy to absorb the walking load impact on the knee, so wood block pavement may be used in the rest areas along highways to provide comfort to pedestrians (Destamatic Oy, 2016). Moreover, wood-plastic composites (WPCs) are attractive due to their low moisture absorption, low density, resistance to biological attack, good dimensional stability, and a combination of high specific stiffness and strength (Valente et al., 2011; Zimmermann, 2013; Sommerhuber, 2015). Less light reflection from the block surface is expected. In addition, the low heat capacity of wood products may reduce the heat gain and heat island effect, which is imposed by the heat waves due to abnormal weather condition these days around the world. Installation time is reduced because wood blocks are much lighter than the typical cement or brick block. In addition, small pieces of cut blocks at the end of block sections, which is vulnerable to exposure damage, may be avoided by making them dovetailed size.

In Japan, research efforts have focused on producing pavement that is comfortable and easy to walk on. Nabeshima et al. (2005) employed the paved surface hardness test (JIS A 6519) to identify a suitable hardness for resilient pedestrian pavement. It was found that a comfort zone lies in the measured range of impact acceleration of roughly $80 \pm 10$ G. Takeuchi et al. (2005) used this range to pursue structural engineering designs for pedestrian pavement with resilience performance based on the elastic modulus obtained in portable FWD 
testing and the impact acceleration from hardness testing of paved surfaces. The elastic modulus range corresponding to the impact acceleration within the hardness range that provides safety and comfort for pedestrians, including the elderly and wheelchair users, was recommended to be 25 to $80 \mathrm{MPa}$ (Takeuchi et al., 2008) and 30 to120 MPa (Takeuchi et al., 2011). Then Higuchi et al. (2011) introduced a simple test that employs a golf ball and suggested that the appropriate flexibility range is 45 to $65 \%$ in terms of the golf ball (GB) coefficient. Modulus of elasticity of the larch lumber can be evaluated through non-destructive methods such as the ultra-sonic method (Oh, 2017; Lee et al., 2018), longitudinal vibration method (Lee et al., 2018), and non-destructive bending method (Lee et al., 2018).

No previous research has been conducted on WPC paver blocks designed for use in pedestrian block pavement or road block pavement. In this study, the first stage covered preliminary tests in terms of flexural strength and dimensional swelling to determine the optimal compounding mix ratio by variation of the WPC ingredients. Once the final optimal WPC product was obtained, a non-porous cement block and a porous cement block, which are both typically used as pedestrian/street blocks in South Korea, were selected and tested in a laboratory in the second stage. Finally, two outdoor test sections of the street paver blocks were built to simulate a basic rest area. The impact absorption properties and swelling properties of the proposed blocks as well as their basic material properties were determined and compared with those of other types of block pavers.

\section{MATERIALS and METHODS}

\subsection{Materials}

Waste wood was provided by Hongcheon Regional
Forestry Cooperative Federation, a governmental agency in South Korea, in May 2018. The waste wood was chipped at the recycling site to a particle size of 2 to $5 \mathrm{~mm}$. It was predominantly composed of thinning-out tree with a high soft wood content. It was reported by Ju and Roh (2017) that wood fiber from waste MDF can be recycled as raw materials for manufacturing of interior decorative accessories.

Recycled low density Polyethylene (PE, manufacturing company: Cheongwoon Industrial co. located at Mungyeong, Gyeongsangbuk-do) as plastics was provided in South Korea. It was used for injection molding and extrusion. Additives included calcium carbonate as a filler, a coupling agent, and zinc stearate as a lubricant for better extrusion.

\subsection{Compounding Design for Wood Block}

The wood blocks were formulated from wood chips, polyethylene (PE), and additives. A total of nine compounding combinations were designed, as shown in Table 1 , by varying the ratios of wood chips and $\mathrm{PE}$, but the proportions of other ingredients was maintained as $17 \%$. It should be noted that determination of wood content in the WPC is crucial and can be examined using either thermogravimetric analysis and

Table 1. Various compounding proportions of WPC for preliminary test

\begin{tabular}{cccc}
\hline Mix-id & Wood chip (\%) & PE (\%) & Additives (\%) \\
\hline \hline P1 & 73 & 10 & 17 \\
P2 & 71 & 12 & 17 \\
P3 & 69 & 14 & 17 \\
P4 & 67 & 16 & 17 \\
P5 & 65 & 18 & 17 \\
P6 & 63 & 20 & 17 \\
P7 & 61 & 22 & 17 \\
P8 & 59 & 24 & 17 \\
P9 & 57 & 26 & 17 \\
\hline
\end{tabular}




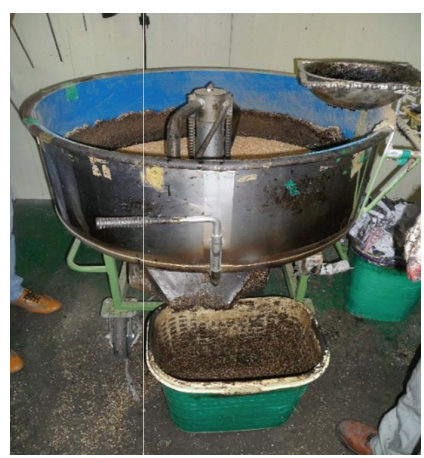

Fig. 1. Compounding with woodchip, PE and additives.

accelerator mass spectrometry (Kwon et al., 2017) or Fourier transform near-infrared and Fourier transform infrared spectroscopy (Cho et al., 2016). Experiments were carried out to determine the optimal mixture with the highest flexural strength value and the least water absorption or dimensional swelling value.

\subsection{Specimen preparation}

The wood chips were oven-dried at around $103{ }^{\circ} \mathrm{C}$ for 24 hours before they were blended with the PE and additives. A laboratory internal mixer with a volume capacity of about $60 \mathrm{~L}$ was used for the compounding processes for $15 \mathrm{~min}$. The temperature for compounding was kept in the range of 140 to $150{ }^{\circ} \mathrm{C}$. To enhance the compounding of wood chips (57-73\%), PE (10-26\%), and calcium carbonate, coupling agents with other necessary ingredients (17\%) were added to the WPC mixtures for fabrication (see Fig. 1). In the extruding process, each compounding mixture was melted and pushed through a die to form the desired 6 to $10 \mathrm{~m}$ long WPC shape to form $50 \mathrm{~mm}$ deep $\times 100 \mathrm{~mm}$ wide blocks with three $20 \mathrm{~mm}$ circular holes at the middle section, as shown in Fig. 2. Then, each block piece was cut into $200 \mathrm{~mm}$ lengths. Finally, the two cut sections of each block were manually varnished with a suitable coating material and air-dried in the laboratory.

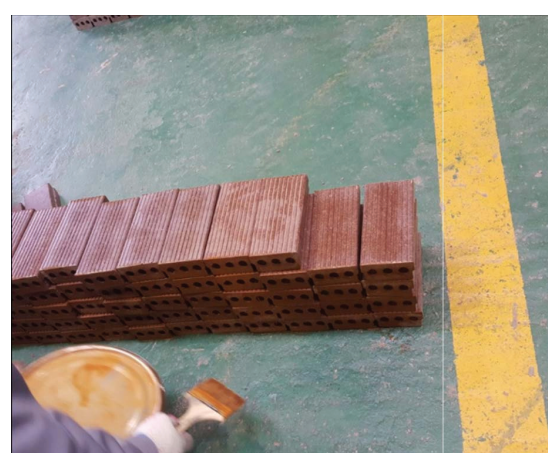

Fig. 2. WPC blocks varnished with oil.

\subsection{Test Methods}

\subsubsection{Flexural strength test}

The test for flexural strength, also defined as the flexural strength, was adapted from KS F 4419 (2016) and tested in flexure using center-point loading. The blocks were loaded at a constant rate of $9.8 \mathrm{MPa} / \mathrm{min}$. until failure occurred. The flexural strength was determined as follows:

$$
\text { Flexural strength }=\frac{3 P l}{2 b d^{2}}
$$

where $P$ : maximum peak load

$l$ : span length

$b$ : average width of the specimen

$d$ : average depth of the specimen

\subsubsection{Water absorption and dimensional swelling}

The test for water absorption was adapted from ASTM D1037 (2012). The specimens were submerged horizontally under $25 \mathrm{~mm}$ of clean water at $23 \pm 2^{\circ} \mathrm{C}$ for 24 hours. The specimens were removed from the water, dried with a clean cloth for 1 minute, and then weighed under the saturated-surface-dry (SSD) condition. Finally the specimens were oven-dried at $103 \pm 2^{\circ} \mathrm{C}$ for 24 hours and weighed in the oven-dried 
(OD) condition. Water absorption was calculated from the difference in weight between the SSD and OD states as follows:

$$
\operatorname{Absorption}(\%)=\frac{W_{S S D}-W_{O D}}{W_{O D}} \times 100
$$

where $W_{S S D}$ : the weight of the block sample in the SSD state

$W_{O D}$ : the weight of the block sample in the OD state

The width, length and thickness swelling was calculated as a percentage of the conditioned dimension, respectively to compute the volume change of the specimen.

$$
\text { Dimensional swelling }(\%)=\frac{t_{S S D}-t_{O D}}{t_{O D}} \times 100 \cdots \cdots
$$

where $t_{S S D}$ : the average thickness, width, length of the block sample in the SSD state

$t_{O D}$ : the average thickness, width, length of the block sample in the OD state

For the water absorption test which is described in 3.1 Preliminary test results for wood blocks in this paper, Procedure A was adopted from KS F 3230 (2013), which is similar to ASTM D1037 (2012). The specimens were immersed at $100^{\circ} \mathrm{C}$ for 5 hours. This procedure was intended to subject the wood specimens to severe conditions because wood specimens are likely to expand under hot and wet weather conditions. Next, the specimens were immersed in water at $23 \pm 2{ }^{\circ} \mathrm{C}$ for 20 minutes, dried with a clean cloth, and weighed. Water absorption was calculated from Eq. (2), but based on $W_{2}$ (the weight of the block sample after immersion) instead of $W_{S S D}$. Likewise, dimensional swelling was calculated from Eq. (3), but based on $t_{2}$ (the average thickness, width, and length of the block sample after immersion) instead of $t_{S S D}$.

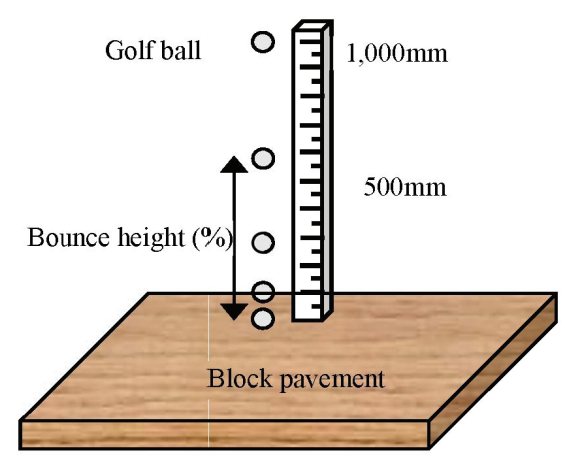

Fig. 3. Measurement of Impact absorbance test.

\subsubsection{Impact absorbance test}

A golf ball (GB) was dropped from a height of $1000 \mathrm{~mm}(\mathrm{H})$ to the block pavement surface and its respective rebounding heights were measured (Fig. 3). The free ball dropping was repeated 20 times (instead of 5 times recommended by Japan Road Association (2007)) for each block paving material, and the ten most similar rebounds (instead of three rebounds recommended by Japan Road Association (2007)) were used to calculate the average rebounding heights $\left(\mathrm{H}_{0}\right)$. Then, the impact absorbance (GB coefficient) was calculated as follows:

$$
\text { Impact absorbance or GBfactor }(\%)=\frac{H_{o}}{H} \times 100 \cdots \cdots
$$

It is widely held that the smaller these factors are, the less bodily impact a pedestrian would receive. The Japan Road Association (2007) and practice usually require a steel ball (SB) test in addition to the golf ball test, in which the SB coefficient reflects rebound resilience. Takeuchi et al. (2008) reported that the GB coefficient correlates well with the elastic modulus of block pavement, but the SB coefficient does not give any meaningful correlation. Thus in our study, only the golf ball test was conducted and test results were correlated with the elastic modulus values. 


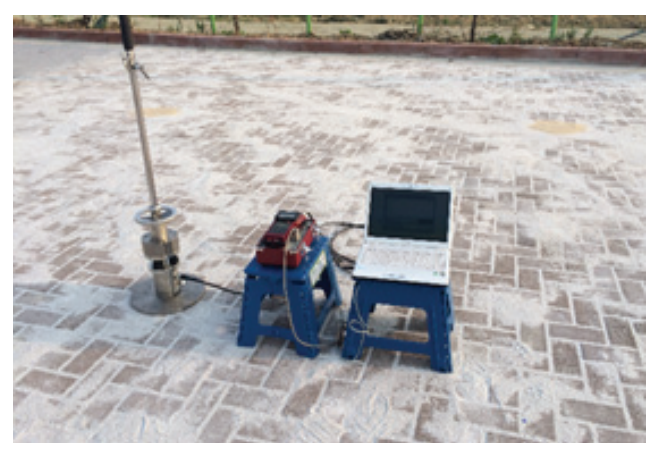

(a) LFWD test apparatus

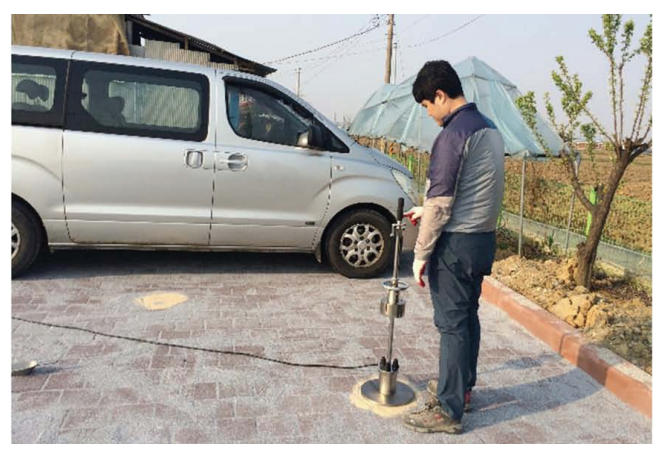

(b) During testing

Fig. 4. Light falling weight deflectometer testing apparatus.

\subsubsection{Light falling weight deflectometer test}

The light falling weight deflectometer (LFWD) test, which is shown in Fig. 4, involves a load cell that is lifted up by hand and dropped to produce an impact on a block pavement (Adam, 2003). In this work, the impact load $(P)$ and elastic deflection $\left(\delta_{c}\right)$ were measured. With the loading radius $(R)$ of $100 \mathrm{~mm}$ and the falling mass of $20 \mathrm{~kg}$, the test was conducted from the dropping height of $1,000 \mathrm{~mm}$. For each block pavement sample, the cell was dropped 5 times and three similar peak deflection values were obtained. The elastic modulus $\left(E_{L F W D}\right)$ was determined using the following equation,

$$
E_{L F W D}=\frac{2\left(1-\mu^{2}\right) \sigma R}{\delta_{c}}
$$

where $\quad \mu$ : poisson's constant

$$
\sigma: \text { applied stress }=\mathrm{P} /\left(R^{2}\right) \text {. }
$$

\section{RESULTS and DISCUSSION}

\subsection{Preliminary test results for wood blocks}

A total of 9 WPC combinations for the preliminary test were mixed according to compounding proportions presented in Table 1 . The flexural strength test set-up

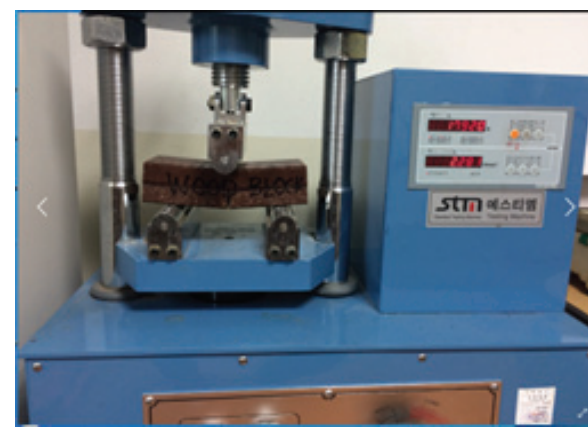

Fig. 5. Flexural strength test for wood block.

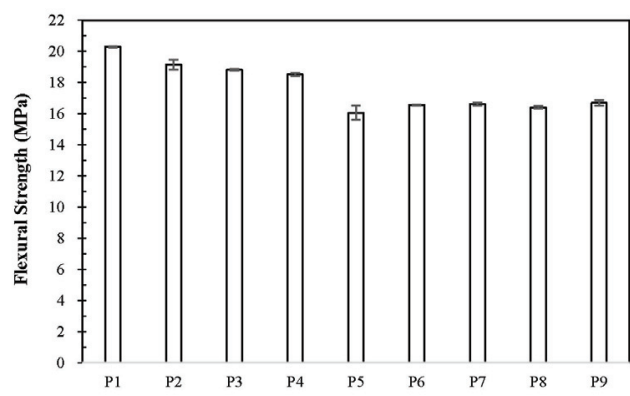

Fig. 6. Flexural strength test results from the preliminary test.

for wood block testing is shown in Fig. 5. Fig. 6 shows the average test results of flexural strengths of the wood block specimens at the age of 7 days, presented with error bars. The flexural strength of the P1 mix (73:10:17 by weight percentage) achieved the highest value of 


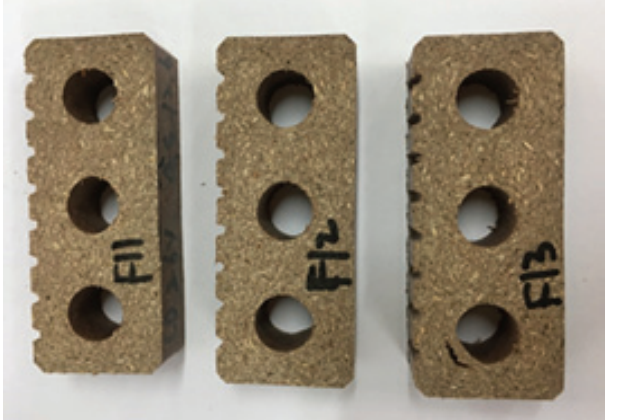

(a) before

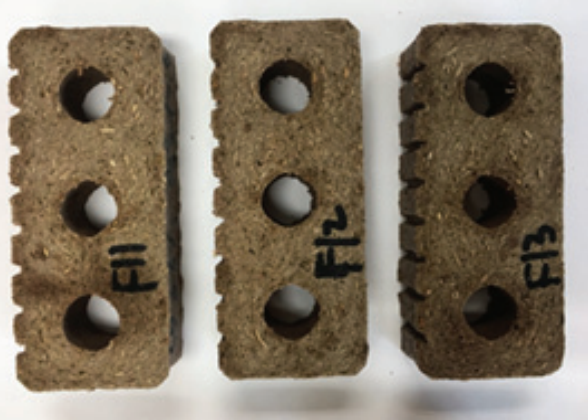

(b) after

Fig. 7. Samples before and after water absorption and dimensional swelling test.

20.3 MPa. From the P1 to P5 specimens, with the addition of PE and a reduced proportion of wood chips, the tendency of decreased flexural strength was observed with the lowest value of 16.1 MPa from P5 specimen. Then for the P6 to P9 mixtures, the flexural strength values were almost identical, ranging from 16.4 MPa to $16.7 \mathrm{MPa}$, but gradually increasing. The change in the flexural strength from the P6 to P9 was not as great at that from P1 to P5.

Next, a water absorption with dimensional swelling test was conducted. Test samples before and after this test are shown in Fig. 7, and the density results are shown in Fig. 8. The density values of the first 4 test samples (P1-P4) were under $1 \mathrm{~g} / \mathrm{cm}^{3}$ so these wood blocks could float away under wet conditions. The density values of the other samples from P6 to P9 ranged from 1.01 to $1.03 \mathrm{~g} / \mathrm{cm}^{3}$, with the maximum value obtained from the P7 sample. Densities of solid jabon and pine were reported as $0.35 \mathrm{~g} / \mathrm{cm}^{3}$ and $0.70 \mathrm{~g} / \mathrm{cm}^{3}$, respectively (Lestari et al., 2018). Fig. 9 shows the water absorption test results. Similar to the decreasing flexural strength pattern, the water absorption of the wood block samples dropped rather sharply from 34.8\% (P1 sample) to $4.08 \%$ (P6 sample) and then gradually increased to $5.3 \%$ (P9 sample). It should be noted that the KS F3230 (2013) specifies the maximum of 8\% for WPC deck floor board. This tendency was also

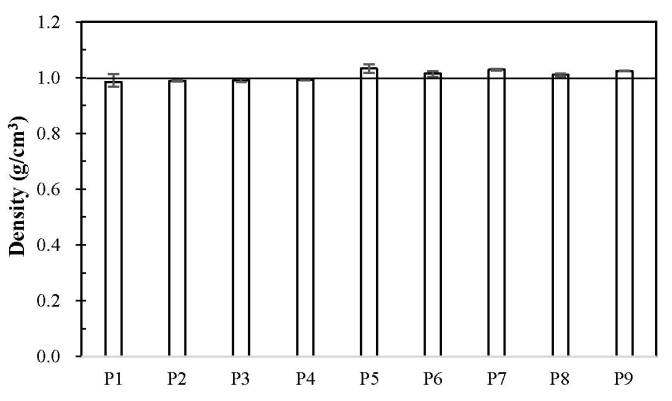

Fig. 8. Density results.

detected from the dimensional swelling test results, which are shown in Fig. 10. For the sample from P4 to $\mathrm{P} 7$, dimensional swelling noticeably dropped, then rebounded in samples P8 and P9. In Fig. 10, it is clearly seen that width swelling does not change at all throughout the samples. However, the expansion in the length and thickness directions was greater than that in the width direction. This is because the block samples were cut into $20 \mathrm{~mm}$ pieces to have the sectional area of $100 \mathrm{~mm} \times 50 \mathrm{~mm}$; thus, the surface coating in that direction came off, and block textures eventually became loose.

From the above preliminary tests by the flexural strength and water absorption as well as dimensional swelling, the P7 mixture was selected as the optimal wood block mix design. 


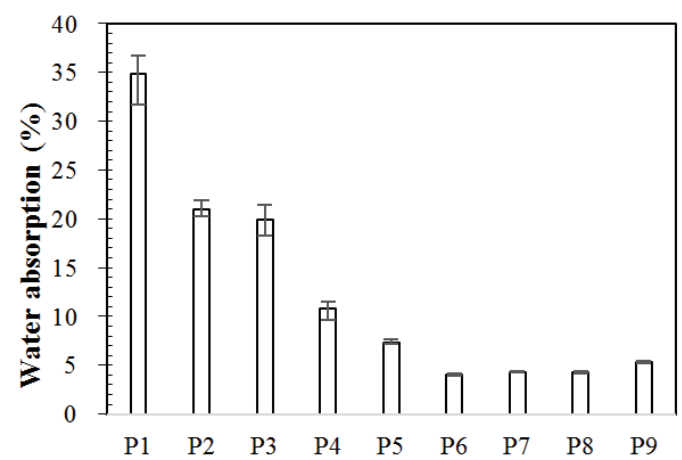

Fig. 9. Water absorption test results.

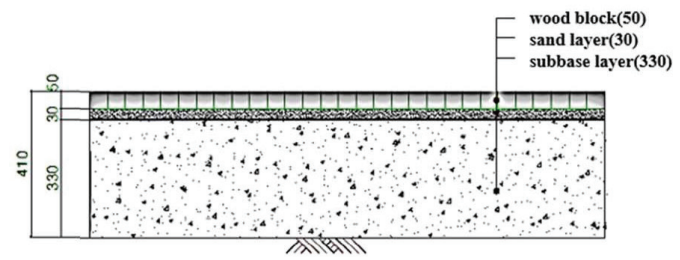

(a) Wood block layers in basic rest area (\#1)

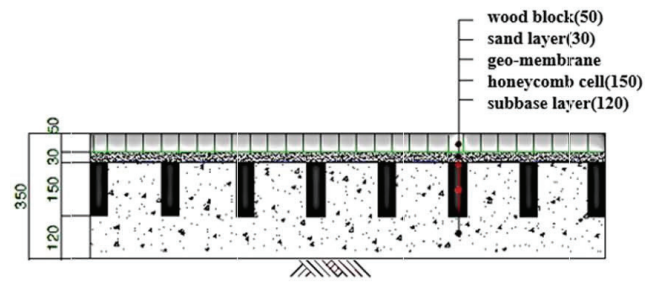

(c) Wood block layers in parking lot (\#2)

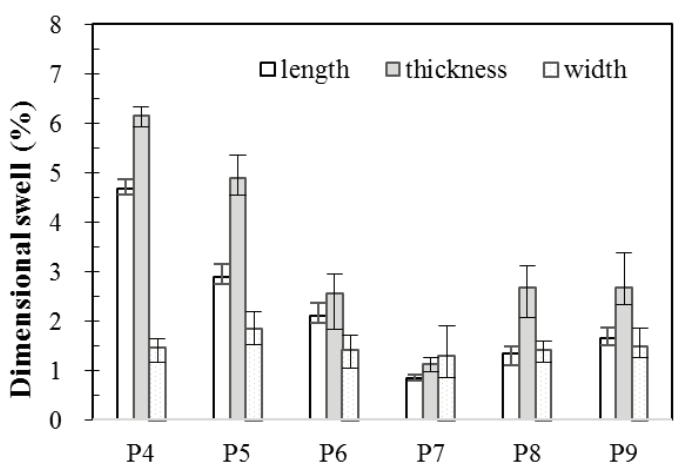

Fig. 10. Dimensional swelling test results.

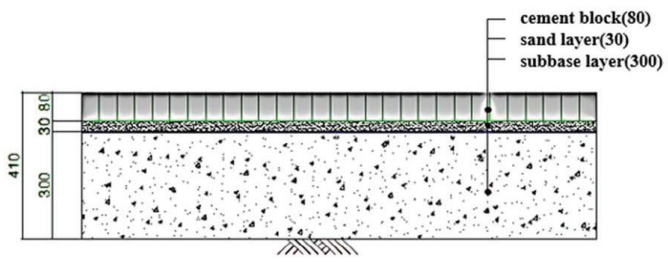

(b) Cement block layers in basic rest area (\#1)

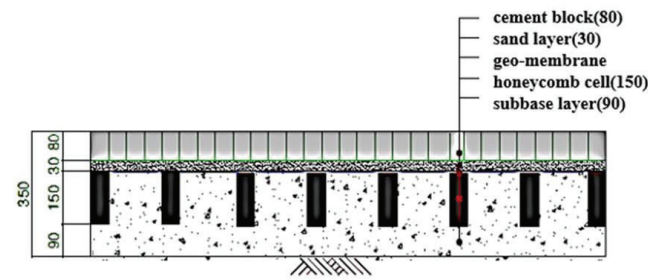

(d) Cement block layers in parking lot (\#2)

Fig. 11. Cross sectional layouts of test sections (\#1 and \#2)

\subsection{Construction of Test Sections}

Once the optimal compounding mixture of P7 had been identified, wood blocks $(100 \mathrm{~mm} \times 200 \mathrm{~mm} \times$ $50 \mathrm{~mm}$ ) were produced in the laboratory for installation in outdoor test sections. For comparison, two typical types of cement blocks were chosen and supplied by local industrial companies: a non-porous cement block $(100 \mathrm{~mm} \times 200 \mathrm{~mm} \times 80 \mathrm{~mm})$ and a porous cement block (200 mm $\times 200 \mathrm{~mm} \times 80 \mathrm{~mm})$. The thickness of the cement blocks was $80 \mathrm{~mm}$, while that of the wood block was $50 \mathrm{~mm}$ because of the greater strength value, which will be subsequently discussed.

Two outdoor test sections were prepared for this study: one simulating for a basic rest area and the other for a parking lot. The sectional dimensions for each layer are shown in Fig. 11. In the basic rest area, the paver blocks were placed on a $30 \mathrm{~mm}$ deep laying course as bedding sand, after compacting of a 300 to $330 \mathrm{~mm}$ thick layer of subbase material beneath it (see 


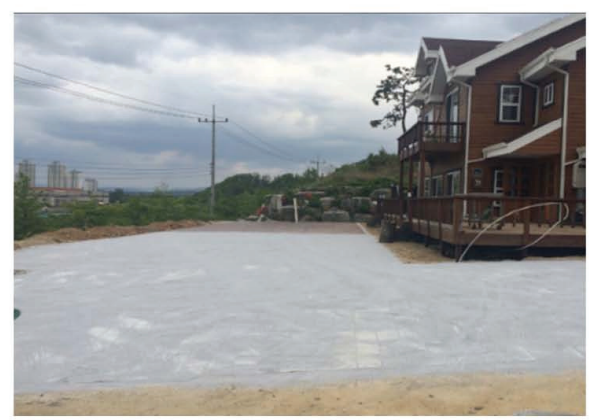

(a) Test section 1: Basic rest area

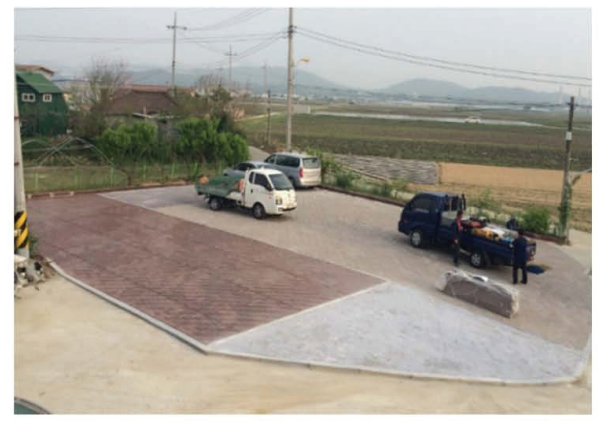

(b) Test section 2: Parking lot

Fig. 12. Photo view of two test sections.

Figs. 11(a)-(b)). In the parking lot (test section \#1), surface layer and sand layer were the same as that in the basic area (test section \#2). Then, a non-woven geo-membrane was used between the sand layer and a honeycomb cell type of $150 \mathrm{~mm}$ thick block, which was placed after compacting of the 90 to $120 \mathrm{~mm}$ thick layer of subbase material beneath it (see Figs. 11(c)-(d)).

The paving was then compacted using a vibrating plate compactor. Fig. 12 shows the final photo views of the test sections. Each test section was 50 to $120 \mathrm{~m}^{2}$. The paving blocks on all the test sections were interlocked to establish a 45 herring-bone layout.

\subsection{Test results of wood blocks and cement blocks}

\subsubsection{Flexural strength}

The test results of flexural strength are shown in Table 2 and depicted in Fig. 13(a). Their relative flexural strength values to non-porous cement block are represented in Fig. 13(b). As mentioned by many researchers (Valente et al., 2011; Zimmermann, 2013; Sommerhuber, 2015), the flexural strength value of the WPC product was about 1.6 times greater than that of the cement blocks. This is because the WPC product is a polymer-based material and has a significantly
Table 2. Flexural strength test results of paving blocks

\begin{tabular}{|c|c|c|c|c|}
\hline \multirow{2}{*}{ Paving } & \multicolumn{3}{|c|}{ Flexural strength } & \multirow{2}{*}{$\frac{(\mathrm{MPa})}{\text { Average }}$} \\
\hline & 1 & 2 & 3 & \\
\hline Wooden block & 15.05 & 15.03 & 14.77 & 14.95 \\
\hline $\begin{array}{l}\text { Non-porous } \\
\text { cement block }\end{array}$ & 8.41 & 7.84 & 10.73 & 8.99 \\
\hline Porous cement block & 8.28 & 7.93 & 8.81 & 8.34 \\
\hline
\end{tabular}

greater flexural strength due to its chemical reaction to form polymer chains in comparison to any other ordinary cementitious-based material.

\subsubsection{Water absorption and dimensional swelling test}

Water absorption with dimensional swelling test results is shown in Figs. 14 and 15. Fig. 14 shows the water absorption test results at 1 day, 3 days, 7 days, and 14 days after immersion in the water container at $20^{\circ} \mathrm{C}$. As seen in Fig. 14, the weight changes in the block specimens slightly increased with elapsed time. The weight changes in the wood block specimens at 14 days resulted in a $2.2 \%$ increase, while those of the non-porous cement block specimens showed about $2.9 \%$ increase, and those of the porous cement block specimens showed about $5.1 \%$ increase. It should be noted that the reason for the greater weight changes 


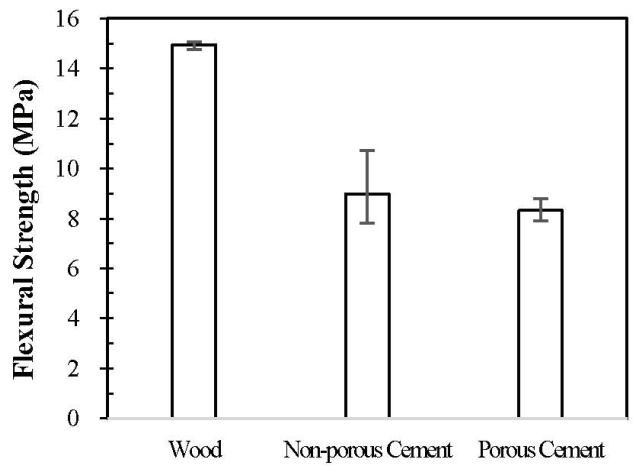

(a) Flexural strength

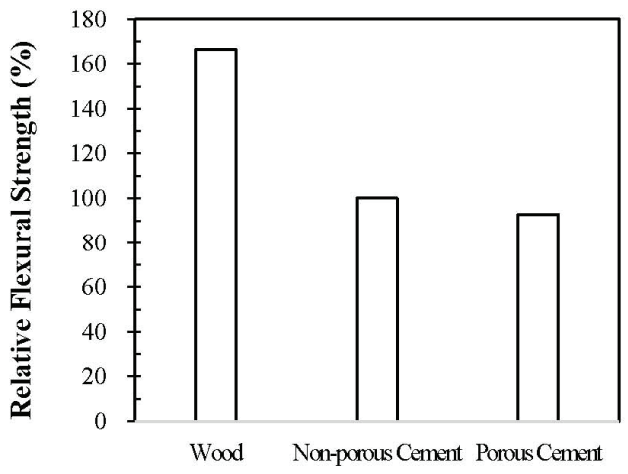

(b) Relative flexural strength

Fig. 13. Flexural strength and relative flexural strength values of diverse block pavements.

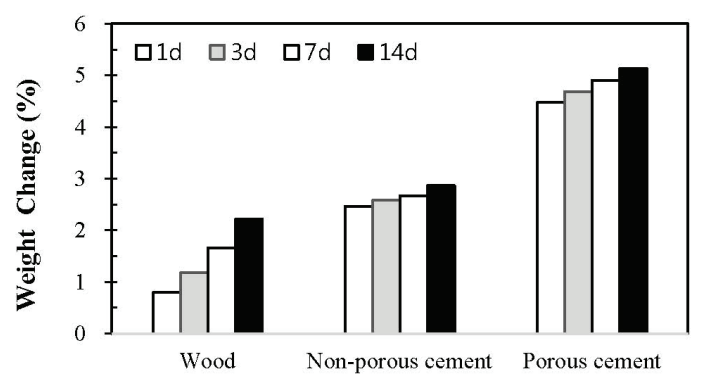

Fig. 14. Water absorption test results.

in the porous cement block specimens is ascribed to more entrapped water inside the pores of those specimens.

The test results of dimensional changes are shown in Fig. 15. Many people have been concerned about expansion tendency of wooden paver blocks. Fig. 15 shows that there is no problem of expansion due to dimensional swelling of wood block specimens. Moreover, the wood block specimens seemed to contract rather than to expand. However, the change values are less than $0.2 \%$, perhaps representing measurement errors. It is reasonably acceptable that test results from other specimens gave less than $0.3 \%$, except for $0.6 \%$ of the non-porous cement block specimen at 3 days, representing measurement error, too. The density value of the wood block specimen was calculated as 1.03 $\mathrm{g} / \mathrm{cm}^{3}$. Thus, these test results clearly showed that the WPC paving blocks are unaffected by water buoyance or volume expansion due to swelling.

\subsubsection{Impact absorbance}

Impact absorbance (it is known as GB coefficient) test results are shown for both test sections in Fig. 16. The golf ball (GB) test, which is provided by Japan Road Association (2007), is required to measure only the first bounce height or the first bounce percentage to the original drop distance. In this study, further repetitive bounce heights were measured to find out whether this impact absorbance tends to keep the same pattern through the other bounce periods or not. As shown from the first bounce period in Fig. 16, the test results clearly showed that from both test sections, the wood paving blocks produced $60.5 \%$ for the rest area and $55.3 \%$ for the parking lot, satisfying the appropriate range of 45 to $65 \%$ for comfort to the pedestrian, recommended by Higuchi et al. (2011). Other paving blocks, such as non-porous or porous cement did not reach to the accepted value. The most obvious trend was observed in the subsequent second and third bounce periods, in which any impact load was shown to be 


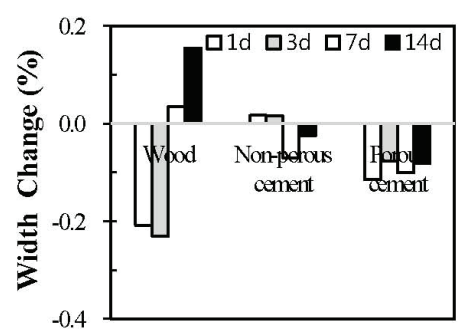

(a) Width change

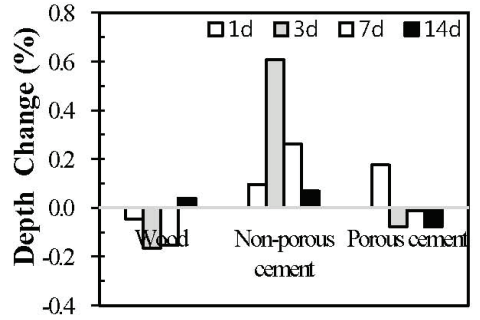

(b) Depth change

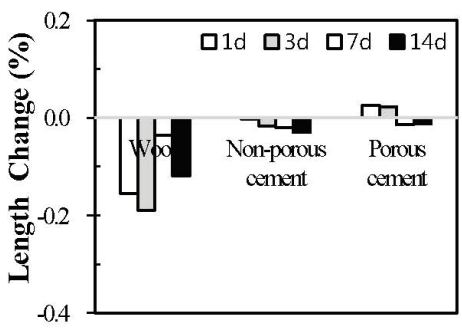

(c) Length change

Fig. 15. Dimensional swelling change test results.

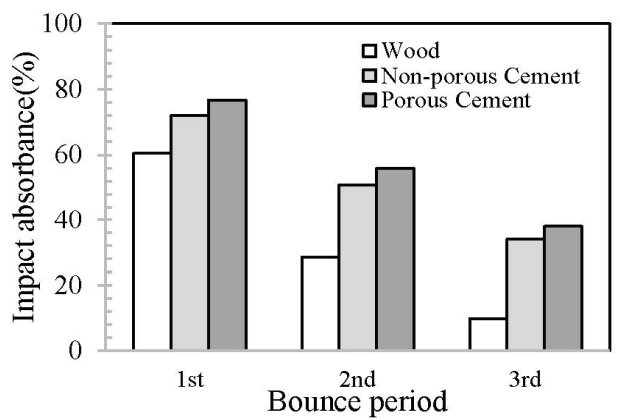

(a) Test section 1 (Reset area)

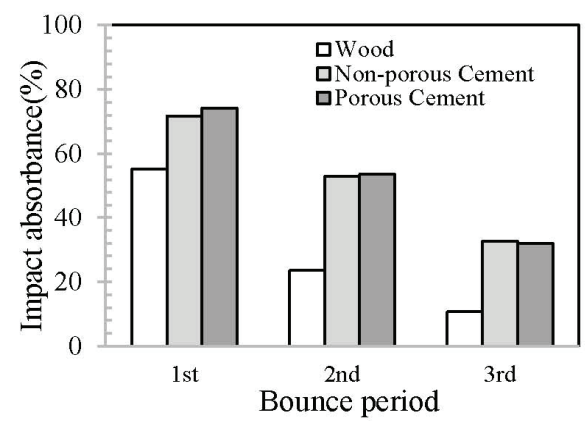

(b) Test section 2 (Parking lot)

Fig. 16. Impact absorbance test results of diverse block pavements by a golf ball test.

remarkably diminished with the wood paving blocks.

\subsubsection{Elastic modulus from LFWD}

Fig. 17 shows elastic modulus values of various wood block pavements which were obtained by the LFWD test on the two test sections. For the wood block pavement section, the elastic modulus values were 102 MPa for the basic rest area (test section \#1) and 140 MPa for the parking lot (test section \#2). In the nonporous cement block test section, the elastic modulus values ranged from 181 to $302 \mathrm{MPa}$, while that of the porous cement block test section was 229 to $259 \mathrm{MPa}$. Although no consistent trend may be obtained from this limited study to estimate the elastic modulus values from the LFWD test, it is evident that the wood block pavement yielded the smallest elastic modulus value among the various tested block pavement systems.

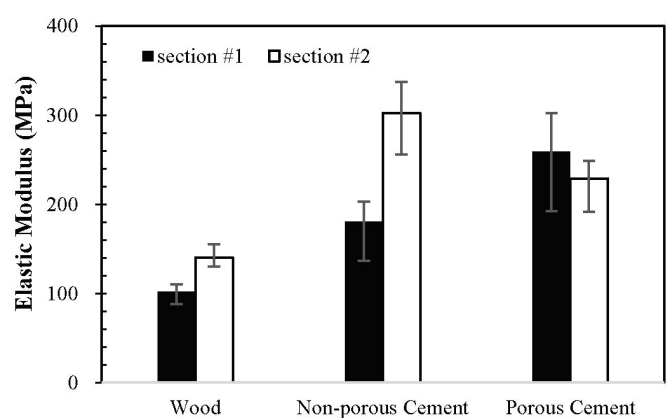

Fig. 17. Elastic modulus values of various block pavements determined by LFWD at two test sections.

As mentioned in the Introduction, the most comfortable and safe hardness range for pedestrians was proposed to be 30 to120 MPa as recommended by Takeushi et al. (2011), while Choi et al. (2017) reported that the elastic modulus values of their 
wood-chip blocks ranged from 48 to $82 \mathrm{MPa}$, varying according to the wood chip to binder ratio. They conducted an LFWD test on wood-chip block specimen placed directly on the ground slab in the laboratory. In test section \#1, the wood block pavement system, which was placed over a $30 \mathrm{~mm}$ deep sand layer plus a $330 \mathrm{~mm}$ deep subbase layer, the modulus guideline (30 to120 MPa) recommended by Takeushi et al. (2011) was satisfied. However, in test section \#2, the wood block pavement system, which was placed over a 30 $\mathrm{mm}$ deep sand layer plus a non-woven geo-membrane plus a $150 \mathrm{~mm}$ thick honeycomb cellblock, plus a 120 $\mathrm{mm}$ deep subbase layer, the modulus guideline was exceeded by $20 \mathrm{MPa}$.

Meanwhile, the Japan Road Association (29) recommended the optimal elastic modulus values from the LFWD test: 5 to $60 \mathrm{MPa}$ for subgrade, 25 to 75 MPa for subbase, 60 to 150 MPa for granular base, and 100 to 300 MPa for asphalt base. Thus, our wood block pavement system, in which the value ranged from 102 to $140 \mathrm{MPa}$, can be considered structurally sound, too.

\section{CONCLUSION}

The first stage in this study covered preliminary tests in terms of flexural strength and dimensional swelling to determine the optimal WPC compounding mixture, by variation of the WPC ingredients. Next, three types of paver blocks (the proposed WPC block, a non-porous cement block, and a porous cement block) were selected and tested in the laboratory. Finally, two outdoor test sections of the road paver blocks were prepared to simulate a basic rest area. From the results of this investigation, the following conclusions can be drawn.

(1) Test results indicated that the flexural strength of the WPC paver block was about 1.6 times greater than the tested cement paver blocks due to its chemical reaction to form polymer chains.

(2) Water absorption with dimensional swelling test results revealed that the weight changes in the block specimens slightly increased with elapsed time. The weight changes in the wood block specimens were $1.7 \%$ at 7 days, which was less than that of the tested cement paver blocks.

(3) The density value of the wood block specimen was calculated as $1.03 \mathrm{~g} / \mathrm{cm}^{3}$. Thus, the WPC block pavement is unaffected by water buoyance or volume expansion due to swelling.

(4) From the two test sections, the impact absorbance test results clearly showed that the wood paving blocks produced 55.3-60.5\% impact absorbance, satisfying the appropriate range of $45-65 \%$ for comfort for pedestrians. Other paving blocks, such as non-porous or porous cement did not reach the accepted value.

(5) From the two test sections, the elastic modulus values were determined from the LFWD test and ranged from 102 to $140 \mathrm{MPa}$. The wood block paving systems marginally satisfied the comfortable and safe hardness range (recommended as 30 to $120 \mathrm{MPa}$ ) from the pedestrians' perspective.

\section{ACKNOWLEDGMENT}

This research was funded by the Shinhwa Co. research fund in S. Korea and partially provided by a National Research Foundation of the 2018 Korea Grant of the Korean Government from the project titled "Structural Performance of Reinforced Concrete Members Made with Revised Equivalent Volume Mix Proportioning Method (2016R1A2B4007932)."

\section{REFERENCES}

Adam, C., Adam, D. 2003. Modelling of the dynamic load plate test with the light falling weight device. Asian Journal of Civil Engineering (Building and 
Housing) 4(2-4): 73-89.

ASTM D1037: Standard Test Methods for Evaluating Properties of Wood-Base Fiber and Particle Panel Materials, ASTM International: West Conshohocken, PA, USA, 2012.

Brown, F.L. 2016. The city is more than human-an animal history of Seattle. University of Washington Press, Seattle and London.

Cho, B., Lohoumi, S., Choi, C., Yang, S., Kang, S. 2016. Study on rapid measurement of wood powder concentration of wood-plastic composites using FT-NIR and FT-IR spectroscopy techniques. Journal of the Korean Wood Science and Technology 44(6): 852-863.

Choi, J., Lee, K. 2004. Performance of sidewalk pavement containing waste-wood chips. Journal of Testing and Evaluation 42(1): 151-161.

Choi, J., Lee, K., Moon, S. 2017. Characteristics of elastic paving materials made of sawdust and urethane resin mixture. Journal of the Korea AcademiaIndustrial Cooperation Society 18(6): 673-680.

Destamatic Oy. 2016. Composite of wood, stone and concrete. Finish Forest Association.

Gibbons, J. 1999. Pavements and surface materials, Nonpoint education for municipal officials, Technical Paper, No. 8, University of Connecticut.

Gwon, J., Lee, D., Cho, H., Chun, S., Choi, D., Lee, S. 2017. Determination of wood flour content in WPC through thermogravimetic analysis and accelerator mass spectrometry. Journal of the Korean Wood Science and Technology 45(5): 572-579.

Higuchi, M., Takeuchi, Y., Okazawa, H., Sato, K. 2011. Study on evaluating the hardness of the side work pavement. International Journal of Environmental and Rural Development 2-1: 77-82.

http:/www.booksupstairs.com/The-preservation-of-str uctural-timber/Prolonging-the-Life-of_6.html.

Japan Road Association. 2007. The handbook of pavement survey and testing, the first volume:
126-129 (in Japanese).

Ju, S., Roh, J. 2017. Manufacture of dyed recycling wood fiber using waste MDF. Journal of the Korean Wood Science and Technology 45(3): 297-307.

Ko, H., Ko, M. 2015. An experimental study on the basic properties of elastic paving materials. Journal of the Korea Academia-Industrial Cooperation Society 16(7): 5021-5028.

KS F3230: Method of test for WPC (Wood Plastic Composites) deck floor board, KATS, Seoul, S. Korea, 2013.

KS F4419: Method of test for concrete interlocking block for sidewalk and road, KATS, Seoul, S. Korea, 2016.

Kyriakodis, H. 2014. Little clubs on a wooden street, Hidden city, Philadelphia.

Lee, I., Cho, S., Hong, S. 2018. Prediction of the MOR of larch lumber. Journal of the Korean Wood Science and Technology 46(1): 93-99.

Lestari, A., Hadi, Y., Hermawan, D., Santoso, A. 2018. Physical and mechanical properties of glued laminated lumber of pine (pinuys merkusii) and Jabon (anthocephalus cadamba). Journal of the Korean Wood Science and Technology 46(2): 143-148.

Ministry of Land, Infrastructure and Transport. 2018. Basic Rest Area. Policy Review, S. Korea,

Nabeshima, M., Yamada, M. 2005. Range of proper hardness for aged about walkway pavement. Official Journals Quarterly of the Japan Society of Civil Engineers 788-67: 117-126.

Oh, S. 2017. Anisotropy of softwood structural lumber using the elastic modulus determined by the ultrasonic nondestructive method. Journal of the Korean Wood Science and Technology 45(1): 20-27.

Richards, R.W. 1897. Hardwood pavements in Sydney, New South Wales. Engineering.

Smith, W.A. 1894. Advantages of Australian hardwood 
for paving. Engineering Record.

Sommerhuber, P., Welling, J., Krause, A. 2015. Substitution potentials of recycled HDPE and wood particles from post-consumer packaging waster in WoodPlastic Composites. Waste Management 46: 76-85.

Stirrat, J. 1898. Notes on wood paving vs macadam in Rangoon. Industrial Engineering.

Sydney Harbor Foreshore Authority. 2012. Paving Part 4 of 5, Types of Wood used for woodblock paving https://www.youtube.com/watch?v=As9N9IfGy6A.

Takeuchi, Y., Sato, K., Aoki, M., Kuni, Y., Sato, K., Yaginuma, H. 2011. Development of pavement design method for walkers in consideration of comfort and safety. Journal of Japan Society of Civil Engineers-E1 67(3): I_1-I_8.

Takeuchi, Y., Sato, K., Aoki, M., Yaginuma, H. 2008. Hardness evaluation of the sidewalk pavement using Portable FWD tester, the proceeding of the 64th JSCE Annual Meeting of the Japan Society of Civil Engineers, (CD-ROMS).

Valente, M., Sarasini, F., Marra, F., Tirillò, J., Pulci, G. 2011. Hybrid recycled glass fiber/wood flour thermoplastic composites: manufacturing and mechanical characterization. Compo. Applied Science and Manufacturing 42(6): 649-657.

Weiss, H.F. 2011. Prolonging the life of paving blocks, The preservation of structural timber. VinDaj, Inc. Whitten, D.O. 1995. Rusty roads: ferrous metal paving materials. Essays in economic and business history XIV: 249-66.

Whitten, D.O. 1997. A century of parquet pavements: Wood as a paving material in the United States and abroad, 1840-1940, Part 1, Nineteenth century origins. Essays in economic and business history XV: 209-26.

Wikipedia. 2016. Nicolson pavement. https:/en.wikipedia. org/w/index.php?title=Nicolson_pavement\&oldid $=739503949$.

Wikipedia. 2018. Rest area. Wikimedia Foundation, Inc.: https://en.wikipedia.org/wiki/Rest_area.

Wittenoom, E.H. 1900. A defense of Australian hardwood pavements. Engineering News.

Zimmermann, M., Zattera, A. 2013. Recycling and reuse of waste from electricity distribution networks as reinforcement agents in polymeric composites. Waste Management 33(7): 1667-1674. 